$$
\begin{aligned}
& N-33 \\
& 148078
\end{aligned}
$$

NASA Technical Memorandum 106037

\title{
Full Wave Characterization of Microstrip Open End Discontinuities Patterned on Anisotropic Substrates Using Potential Theory
}

\section{S.S. Toncich}

Lewis Research Center.

$=$ Cleveland, Ohio

R.E. Collin

Case Western University

Cleveland, Ohio

and

K.B. Bhasin

Lewis Research Center

Cleveland, Ohio

Prepared for the

Institute of Electrical and Electronics Engineers, MTT-S International

Microwave Symposium

sponsored by the Institute of Electrical and Electrönics Engineers Microwave Theory and Techniques Society

Atlanta, Georgia, June 12-18, 1993

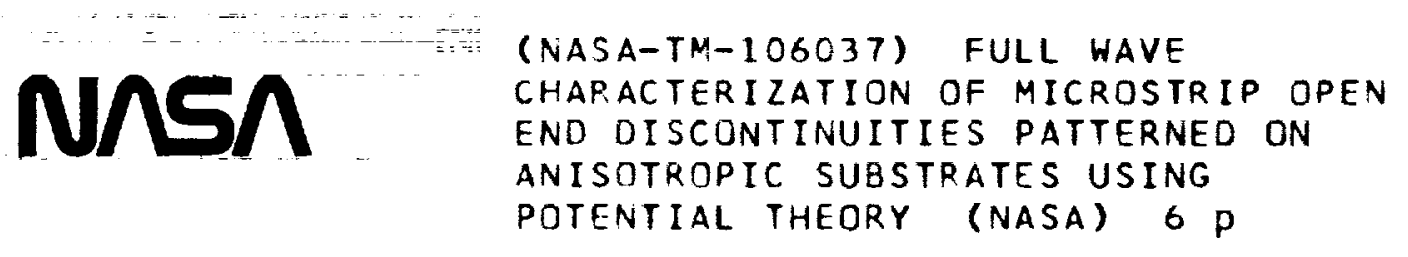

N93-20259

(NASA-TM-106037) FULL WAVE

CHARACTERIZATION OF MICROSTRIP OPEN

END DISCONTINUITIES PATTERNED ON

ANISOTROPIC SUBSTRATES USING

P. 6

6 
$-1$

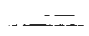

$-1+\sin -1$

$+\div=-\cdots$

$=\cdots$

$-=$

$--\cos$

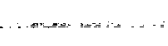

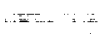

$\ldots$ 


\title{
FULL WAVE CHARACTERIZATION OF MICROSTRIP OPEN END DISCONTINUITIES PATTERNED ON ANISOTROPIC SUBSTRATES USING POTENTIAL THEORY
}

\author{
S.S. Toncich* \\ National Aeronautics and Space Administration \\ Lewis Research Center \\ Cleveland, Ohio 44135 \\ R.E. Collin \\ Department of Electrical Engineering \& Applied Physics \\ Case Western Reserve University \\ Cleveland, Ohio 44106 \\ and
}

K.B. Bhasin

National Aeronautics and Space Administration

Lewis Research Center

Cleveland, Ohio 44135

$\underline{\text { Abstract }}$

A technique for the full wave characterization of microstrip open end discontinuities fabricated on uniaxial anisotropic substrates using potential theory is presented. The substrate to be analyzed is enclosed in a cut-off waveguide, with the anisotropic axis aligned perpendicular to the airdielectric interface. A full description of the sources on the microstrip line is included with edge conditions built in. Extention to other discontinuities is discussed.

\section{Introduction}

While there is extensive data available on the microwave characterization of a variety of microstrip discontinuities using both quasi-static [1-3] and full wave techniques [4-6], the characterization has been restricted to isotropic substrates. To date, there is no published data regarding microstrip discontinuities patterned on anisotropic substrates. Some very useful microwave substrates however, like sapphire, are anisotropic and so any discontinuity structures fabricated on them can not be properly characterized by the techniques that have been developed for isotropic dielectric substrates.

A technique for the full wave characterization of microstrip open ends fabricated on lossless uniaxial anisotropic substrates has been developed and is presented here. It is based on a dynamic source reversal technique that uses potential theory [7], which is a generalization of the charge resversal technique introduced several years ago [1]. The discontinuity is enclosed in a waveguide of infinite extent whose dimensions are such that the guide is cut-off for the propagating frequency on the microstrip. All sources on the microstrip are represented, and the technique does not require a model for the source exitation.

\section{Dynamic Source Reversal Technique}

The anisotropic axis of the substrate is aligned perpendicular to the air-dielectric interface as shown in Fig. 1. The anisotropic dielectric may be represented as a tensor quantity given by

$\kappa(y)=\kappa(\mathbf{y}) \mathbf{I}+\left[\kappa_{\mathbf{y}}(\mathrm{y})-\kappa(\mathbf{y})\right] \mathbf{a}_{\mathbf{y}} \mathbf{z}$

where $I$ is the unit dyad and $x(y)=x_{y}(y)=1$ for $y>h$. The microstrip line is assumed to be infinitely thin and located at a height $y=\mathrm{h}^{+}$. In terms of the sources on the microstrip line, the scalar and vector potentials, $\Phi$ and $A$ respectively, for the dielectric loaded waveguide may be determined from

$$
\begin{aligned}
& \left(\nabla^{2}+\kappa k_{0}{ }^{2}\right) A_{x}=-\mu_{0} J_{x} \\
& \left(\nabla^{2}+\kappa k_{0}{ }^{2}\right) A_{z}=-\mu_{0} J_{x} \\
& \left(\nabla^{2}+\kappa k_{0}{ }^{2}\right) A_{y}=j \omega \mu_{0} \epsilon_{0}(\kappa-1) \Phi(h) \delta(y-h) \\
& \quad+j \omega \mu_{0} \epsilon_{0}\left(\kappa_{y}-\kappa\right) \partial \Phi / \partial y \\
& {\left[\kappa\left(\partial^{2} / \partial x^{2}+\partial^{2} / \partial z^{2}\right)+\partial(\kappa(y) \partial / \partial y) / \partial y+\kappa^{2}(y) k_{0}{ }^{2}\right] \Phi} \\
& =-\rho / \epsilon_{0}+j \omega\left(\kappa_{y}-1\right) A_{y}(h) \delta(y-h)-j \omega\left(\kappa_{y}-\kappa\right) \partial A_{y} / \partial y
\end{aligned}
$$

The potentials appearing in Eqs. (2) to (5) are obtained from the appropriate Green's functions and the corresponding sources using

$$
A_{x, z}(x, h, z)=\mu_{0} \iint_{x^{\prime} z^{\prime}} G_{x, z}\left(x, h, z ; x^{\prime}, h, z^{\prime}\right) J_{x, z}\left(x^{\prime}, h, z^{\prime}\right) d x^{\prime} d z^{\prime}
$$

\footnotetext{
"National Research Council-NASA Research Associate at Lewis Research Center.
} 


$$
\epsilon_{0} \Phi(\mathbf{x}, \mathbf{h}, \mathbf{z})=\iint_{\mathbf{x}^{\prime} z^{\prime}} G_{\Phi}\left(\mathbf{x}, \mathbf{h}, \mathbf{z} ; \mathbf{x}^{\prime}, \mathbf{h}, \mathbf{z}^{\prime}\right) \rho\left(\mathbf{x}^{\prime}, \mathbf{h}, \mathbf{z}^{\prime}\right) \mathrm{d} \mathbf{x}^{\prime} \mathrm{d} \mathbf{z}^{\prime}
$$

From these potentials the electric field components are found using

$E_{x}=-j \omega A_{x}-\partial \Phi / \partial x$

$E_{y}=-j \omega A_{y}-\partial \Phi / \partial y$

$E_{z}=-j \omega A_{z}-\partial \Phi / \partial z$

where it is required that for this particular geometry $\mathrm{E}_{\mathbf{x}}$ and $E_{z}$ vanish on the microstrip. The fields thus obtained are expressed in terms of LSE and LSM modes of the dielectric loaded waveguide. The anisotropic effect appears only in the LSM mode terms, which are present in $A$ and $\Phi$. The LSE modes are unchanged from those obtained for the isotropic case.

A complete set of dominant mode sources on the microstrip are represented; the longitudinal and transverse currents, as well as the charge on the microstrip line, with appropriate edge conditions built in. For a wide range of practical open end discontinuities, a valid approximation is that $J_{x}=0$, so therefore $A_{x}=0$. As a result, only the boundary condition $E_{\mathbf{z}}=0$ is required for this problem.

A line terminated at $\mathbf{z}=0$, thus forming an open end, would create reflected dominant mode sources on the line, along with perturbed sources localized near the discontinuity. The total source distribution on an open end may be written as

$$
\begin{aligned}
& \mathrm{J}_{\mathrm{z}}\left(\mathrm{x}^{\prime}, \mathrm{h}, \mathrm{z}^{\prime}\right)=\mathrm{J}_{0 \mathrm{z}}\left(\mathrm{x}^{\prime}\right)\left(\mathrm{e}^{-\mathrm{j} \beta \mathrm{z}^{\prime}}-\operatorname{Re} \mathrm{e}^{+\mathrm{j} \beta \mathrm{z}^{\prime}}\right)+\mathrm{J}_{1 \mathrm{z}}\left(\mathrm{x}^{\prime}, \mathrm{z}^{\prime}\right) \\
& \rho\left(\mathrm{x}^{\prime}, \mathrm{h}, \mathrm{z}^{\prime}\right)=\rho_{0}\left(\mathrm{x}^{\prime}\right)\left(\mathrm{e}^{-\mathrm{j} \beta \mathrm{z}^{\prime}}+\operatorname{Re}^{+\mathrm{j} \beta \mathrm{z}^{\prime}}\right)+\rho_{1}\left(\mathrm{x}^{\prime}, \mathrm{z}^{\prime}\right)
\end{aligned}
$$

for $\mathrm{z}^{\prime} \leq 0$, where $\mathrm{J}_{0 \mathrm{z}}, \rho_{0}$ and $\beta$ are the yet to be determined amplitudes and propagation constant, respectively of the dominant microstrip mode, $\mathrm{R}$ is an unknown reflection coefficient, and $J_{1}$ and $\rho_{1}$ represent the perturbed source amplitudes near the open end. Weighted Chebychev polynomials are used to represent the sources in $x$ for both dominant and perturbed sources, while triangle and pulse functions are used to represent the perturbed sources in $z$.

Equations (9) and (10) may be written as

$$
\begin{array}{r}
J_{\mathrm{s}}\left(\mathrm{x}^{\prime}, \mathrm{h}, \mathrm{z}^{\prime}\right)=\left[\mathrm{j}(1+\mathrm{R}) \mathrm{J}_{0 \mathrm{z}}\left(\mathrm{x}^{\prime}\right)\left(\mathrm{B}_{\mathrm{in}} \cos \left(\beta \mathrm{z}^{\prime}\right)-\sin \left(\beta \mathrm{z}^{\prime}\right)\right)\right. \\
\left.\quad+\mathrm{jJ} \mathrm{J}_{1 \mathrm{z}}\left(\mathrm{x}^{\prime}, \mathrm{z}^{\prime}\right)\right] \cdot\left[1-\mathrm{U}\left(\mathrm{z}^{\prime}\right)\right](11) \\
\begin{array}{r}
\rho\left(\mathrm{x}^{\prime}, \mathrm{h}, \mathrm{z}^{\prime}\right)=\left[(1+\mathrm{R}) \rho_{0}\left(\mathrm{x}^{\prime}\right)\left(\mathrm{B}_{\mathrm{in}} \sin \left(\beta \mathrm{z}^{\prime}\right)+\cos \left(\beta \mathrm{z}^{\prime}\right)\right)\right. \\
\left.+\rho_{1}\left(\mathrm{x}^{\prime}, \mathrm{z}^{\prime}\right)\right] \cdot\left[1-\mathrm{U}\left(\mathrm{z}^{\prime}\right)\right](12)
\end{array}
\end{array}
$$

where $U\left(z^{\prime}\right)$ is the Heavyside unit step function which is 0 for $z^{\prime}<0$ or 1 for $z^{\prime}>0$, and $j B_{\text {in }}=(1-R) /(1+R)$ is the normalized input susceptance for the open end. In Eqs. (11) and (12) the dominant mode sources are assumed to exist for $-\infty \leq z^{\prime} \leq \infty$. Then dominant mode sources for $z^{\prime}>0$ are subtracted away to create the terms that multiply the $(1+R)$ coefficient in (11) and (12). Since the amplitudes of $J_{1}$ and $\rho_{1}$ are arbitrary at this point, they may be defined so as to include the $(1+R)$ term. Now the $(1+R)$ term is common to all of the source terms, so it may be normalized to 1.0. Using Eqs. (11) and (12) in Eqs. (6) and (7) and substituting into Eq. (8) gives the electric field in terms of the sources on the open end microstrip line. When the requirement that $\mathrm{E}_{z}=$ 0 on the microstrip is enforced, the terms corresponding to the dominant mode on the infinite line already satisfy the boundary condition on the strip, so they drop out. The sources existing for $z^{\prime}>0$ may be considered "source reversed" terms which produce an impressed field in the reigon $z \leq 0$ but localized near the discontinuity. The factor $(1+R)$ can be included into the arbitrary amplitude of the dominant mode sources. Thus, apart from the unknown parameter $B_{i n}$, the dominant mode sources in $z^{\prime}>0$ produce a known forcing function in the strip for $z^{\prime}<0$. The electric field produced by the perturbed sources $J_{1}$ and $\rho_{1}$, must cancel the tangential component of the applied field for $\mathrm{z} \leq 0$. A modified perturbation technique [8] is used to determine the unknown dominant mode amplitudes and propagation constant for an infinite line. The method of moments is then used to reduce the resulting integral equation to a matrix equation which can be solved for the unknown input admittance $B_{i n}$, as well as for $J_{1 z}$ and $p_{1}$. Only one matrix inversion is required to find $\dot{B}_{\text {in }}$.

\section{Results}

The pulse width, $\Delta$, of the expansion functions was chosen to be $0.32 \mathrm{~mm}$ at $f=2.0 \mathrm{GHz}$ (or $\Delta \simeq 0.0053 \lambda_{\mathrm{g}}$ for sapphire). This puise width guaranteed a converged value for $B_{\text {in }}[7]$ for all of the examples presented. To verify the accuracy of the theory as well as the resulting program, the program was checked for the isotropic case, and was able to duplicate data obtained in [1] and [7].

Table I shows the results obtained using this technique for several different anisotropic substrates as a function of microstrip line width. The open circuit capacitance, $\mathrm{C}_{o c}$ is found using $\mathrm{C}_{o c}=\mathrm{B}_{\mathrm{in}} / \omega \mathrm{Z}_{0}$, where the characteristic impedance $Z_{0}$ is obtained from a computer program developed on the basis of the theory presented in [8] for the characterization of infinite microstrip lines with sidewalls, but no top cover. To justify using values of $Z_{0}$ thus obtained, calculations performed for a microstrip line with an air dielectric showed less than $2 \%$ difference in $Z_{0}$ values obtained with and without a top cover. Table II shows the variation of $\mathrm{C}_{\mathrm{oc}}$ as a function of line width for sapphire, and compares the results obtained for a substrate with an isotropic dielectric constant of 9.4, as well as for an isotropic dielectric constant of 11.6. Table III shows the effects of fixed waveguide dimensions on $B_{\text {in }}$ and $C_{\alpha}$ as a function of frequency of the propagating microstrip mode. For low frequencies, $B_{\text {in }}$ varies linearly with frequency, starting to deviate as the frequency increases, this effect becomes more pronounced until the cut off frequency of the $E_{11}$ waveguide mode is reached. This effect may be overcome by either frequency scaling the input parameters or by adjusting the waveguide dimensions accordingly. 
The BASIC computer program developed to implement this technique can be executed on a personal computer with as little as $640 \mathrm{~K}$ of RAM. Other discontinuity structures can be characterized in a similar manner. The technique is computationally efficient, there is no need to model the source excitation, and the admittance can be solved for directly in the case of a one port network. All integrals involving the expansion and testing functions are performed analytically so no numerical integrations are necessary, and the dominant portions of slowly converging series can be extracted and summed into closed form.

This technique can be extended to rapidly and accurately characterize a number of other commonly used discontinuity structures, especially "coaxial" two port structures such as asymmetrical gaps and steps in width. To characterize a two port structure in terms of an equivalent "Tee" or " $\mathrm{Pi}^{\text {" }}$ network, the Tangent Plane method [9] can be used to extract parameter values.

\section{References}

1. P. Silvester, and P. Benedek, "Equivalent capacitance of microstrip open circuits," IEEE Trans. Microwave Theory Tech., vol. MTT-20, pp. 511-516, 1972.

2. P. Silvester, and P. Benedek, "Equivalent capacitance of microstrip gaps and steps," IEEE Trans. Microwave Theory Tech., vol. MTT-20, pp. 729-733, 1972.
3. P. Anders, and F. Arndt, "Microstrip discontinuity capacitances and inductances for double steps, mitered bends with arbitrary angle, and asymmetric right angle bends," IEEE Trans. Microwave Theory Tech., vol. MTT-28, pp. 1213-1217, 1980.

4. R.H. Jansen, "Hybrid mode analysis of end effects of planar microwave and millimeter wave transmission lines," IEEE proc. Pt. H: Microwaves, Optics, Antennas, vol. MTT-128, no. 2, pp. 77-86, 1981.

5. J.C. Rautio, and R.F. Harrington, "An electromagnetic time-harmonic analysis of shielded microstrip circuits," IEEE Trans. Microwave Theory Tech., vol. MTT-35, pp. 726-731, 1987.

6. R.W. Jackson, "Full wave, finite element analysis of irregular microstrip discontinuities," IEEE Trans. Microwave Theory Tech., vol. MTT-37, pp. 81-89, 1989.

7. S.S. Toncich, and R.E. Collin, "Characterization of microstrip discontinuities by a dynamic source reversal technique using potential theory, in 14th. Triennial URSI International Symposium on Electromagnetic Theory, pp. 520-523 (Sydney, Australia), 1992.

8. B.E. Kretch, and R.E. Collin, "Microstrip dispersion including anisotropic substrates," IEEE Trans. on Microwave Theory Tech., vol. MTT-35, pp. 710-718, 1987.

9. R.E. Collin, Field theory of guided waves. New York: McGraw Hill, Ch. 5, 1960.
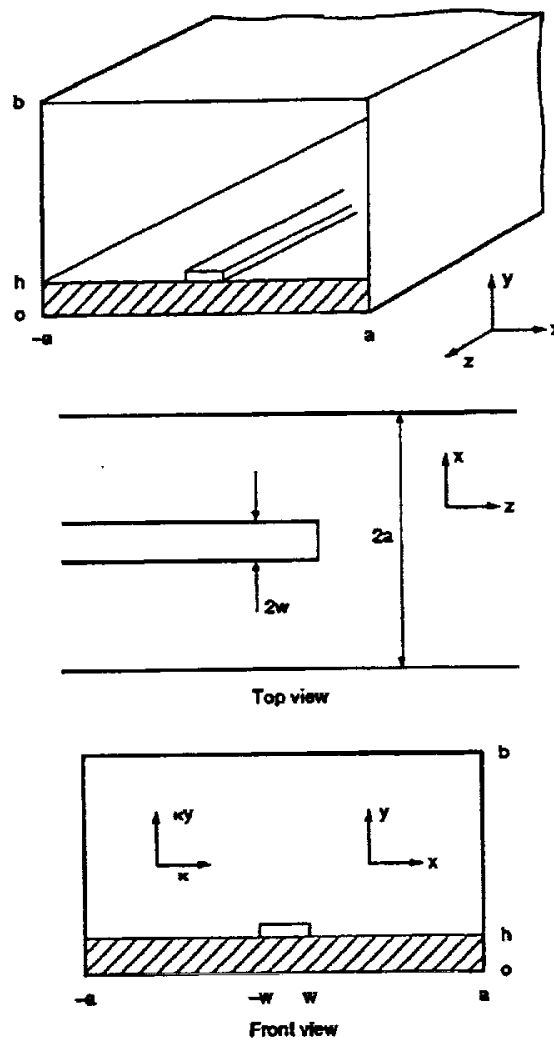

Figure 1.-Shiolded mikrostip goometry. 
TABLE I.-OPEN CIRCUIT CAPACITANCE, $C_{O C}$, FOR SEVERAL ANISOTROPIC DIELECTRIC MATERIALS. FREQUENCY $=2.0 \mathrm{GHz}, \mathrm{h}=1.0 \mathrm{~mm}$, $\mathrm{b}=11 \mathrm{~mm}, 2 \mathrm{a}=20 \mathrm{~mm}$ FOR $\mathrm{W} / \mathrm{h}<4.0$ ELSE $2 \mathrm{a}=10$ (W/ $/ \mathrm{h}) . \mathrm{z}_{0}$ VALUES

OBTAINED FROM REF. 8. UNITS ARE pF/METER FOR $C_{O C}$.

\begin{tabular}{|c|c|c|c|c|c|c|c|}
\hline & & \multicolumn{6}{|c|}{$\mathrm{W} / \mathrm{h}$} \\
\hline & & 0.25 & 0.5 & 1.0 & 2.0 & 4.0 & 6.0 \\
\hline PTFE/Woven glass & $\boldsymbol{k}_{\mathbf{0}}$ & 1.914 & 1941 & 1.981 & 2.042 & 2.129 & 2.182 \\
\hline$x=2.84$ & $Z_{0}$ & 150.5 & 119.9 & 90.02 & 62.46 & 39.82 & 29.50 \\
\hline$x_{y}=2.45$ & $C_{\alpha} / W$ & 29.85 & 23.71 & 19.90 & 17.66 & 16.29 & 15.60 \\
\hline Boron nitride & $\boldsymbol{k}_{\mathrm{a}}$ & 2.676 & 2.699 & 2.738 & 2.808 & 2.922 & 2.999 \\
\hline$K=5.12$ & $\mathbf{Z}_{0}$ & 127.4 & 101.7 & 76.68 & 53.38 & 34.09 & 25.25 \\
\hline$k_{y}=3.4$ & $\mathrm{C}_{\alpha} / \mathrm{W}$ & 43.04 & 33.95 & 28.27 & 24.84 & 22.72 & 21.66 \\
\hline Sapphire & $\mathrm{k}_{\mathrm{e}}$ & 6.724 & 7.012 & 7.647 & 8.145 & 9.007 & 9.514 \\
\hline$K=9.4$ & $Z_{o}$ & 80.90 & 63.65 & 46.94 & 31.82 & 19.80 & 14.52 \\
\hline$K_{y}=11.6$ & $\mathrm{C}_{\alpha} / \mathrm{W}$ & 80.36 & 65.56 & 56.38 & 50.95 & 47.43 & 45.35 \\
\hline Epsilam 10 & $\kappa_{\varepsilon}$ & 6.885 & 7.047 & 7.306 & 7.721 & 8.308 & 8.679 \\
\hline$K=13$ & $Z_{0}$ & 79.90 & 63.44 & 47.39 & 32.61 & 20.55 & 15.14 \\
\hline$x_{y}=10.3$ & $C_{2} / w$ & 95.28 & 76.26 & 64.44 & 57.35 & 52.93 & 50.49 \\
\hline
\end{tabular}

TABLE II.-VARLATION OF $C_{O C}$ AS A FUNCTION OF LINE WIDTH FOR SAPPHIRE, $\mathrm{k}=9.4, \mathrm{k}_{\mathrm{y}}=11.6$ COMPARED TO

THAT OF AN ISOTROPIC DIELECTRIC. FREQUENCY

$=2.0 \mathrm{GHz}, \mathrm{h}=1.0 \mathrm{~mm}, \mathrm{~b}=11 \mathrm{~mm}, 2 \mathrm{a}=20 \mathrm{~mm}$ FOR $\mathrm{W} / \mathrm{h}<4.0$, ELSE $2 \mathrm{a}=10(\mathrm{~W} / \mathrm{h})$. UNITS ARE $\mathrm{pF} / \mathrm{METER}$ FOR $\mathrm{C}_{\mathrm{OC}}$.

\begin{tabular}{|l|l|l|l|l|l|l|l|}
\hline \multicolumn{2}{|c|}{} & \multicolumn{6}{|c|}{ W/h } \\
\cline { 2 - 7 } \multicolumn{2}{|c|}{} & 0.25 & 0.5 & 1.0 & 2.0 & 4.0 & 6.0 \\
\hline $\begin{array}{l}\text { Sapphire } \\
K=9.4 \\
K_{y}=11.6 \\
\kappa=9.4 \\
K_{y}=9.4 \\
x_{=11.6}=11.6\end{array}$ & $C_{\alpha} / W$ & 80.36 & 65.56 & 56.38 & 50.95 & 47.43 & 45.35 \\
$K_{y}=11.6$ & $C_{\alpha} / W$ & 90.18 & 73.27 & 62.58 & 56.21 & 52.13 & 49.77 \\
\hline
\end{tabular}

TABLE III-VARIATION OF THE NORMALZED INPUT SUSCEPT. ANCE, $B_{\text {in }}$, AND OPEN CIRCUIT CAPACITANCE, $\mathrm{C}_{\infty}$, WITH FREQUENCY. WAVEGUIDE DIMENSIONS ARE $2 a=20 \mathrm{~mm}$, $\mathrm{b}=11 \mathrm{~mm}$ AND $\mathrm{h}=1 \mathrm{~mm}$.

\begin{tabular}{|c|c|c|}
\hline $\begin{array}{c}\text { Frequency, } \\
\mathrm{GHz}\end{array}$ & $\mathrm{B}_{\mathrm{lz}}$ & $\mathrm{C}_{\alpha}(\mathrm{pF} / \mathrm{m})$ \\
\hline 0.5 & 0.008388 & 56.26 \\
1.0 & .016776 & 56.26 \\
2.0 & .033256 & 56.38 \\
4.0 & .068373 & 56.85 \\
6.0 & .167738 & 90.81 \\
\hline
\end{tabular}




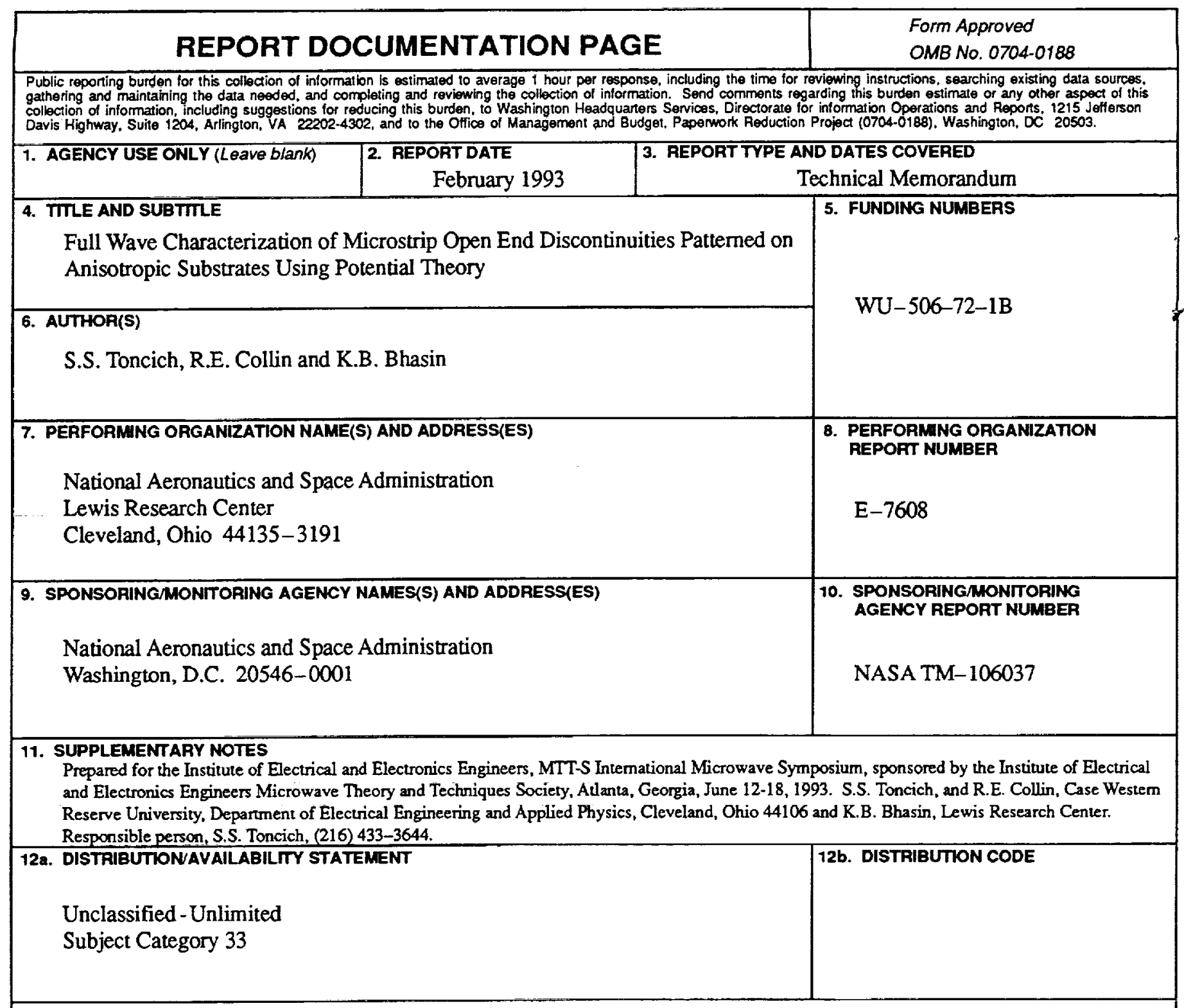

\section{ABSTRACT (Maximum 200 words)}

A technique for a full wave characterization of microstrip open end discontinuities fabricated on uniaxial anisotropic substrates using potential theory is presented. The substrate to be analyzed is enclosed in a cutoff waveguide, with the anisotropic axis aligned perpendicular to the air-dielectric interface. A full description of the sources on the microstrip line is included with edge conditions built in. Extention to other discontinuities is discussed.

\section{SUBJECT TERMS}

Anisotropic substrate; Microstrip discontinuity, Microstrip open-ends; Microwave characterization

\begin{tabular}{|c|c|}
\hline 17. SECURTY CLASSIFICATION & 18. SECURITY CLASSIFICATION \\
OF REPORT & OF THIS PAGE \\
Unclassified & Unclassified
\end{tabular}

19. SECURTY CLASSIFICATION OF ABSTRACT Unclassified

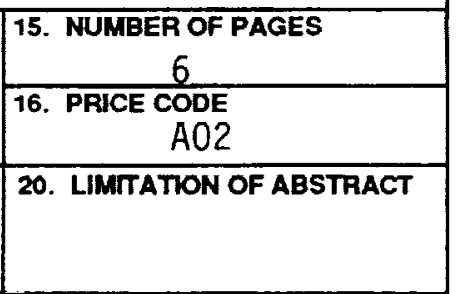

